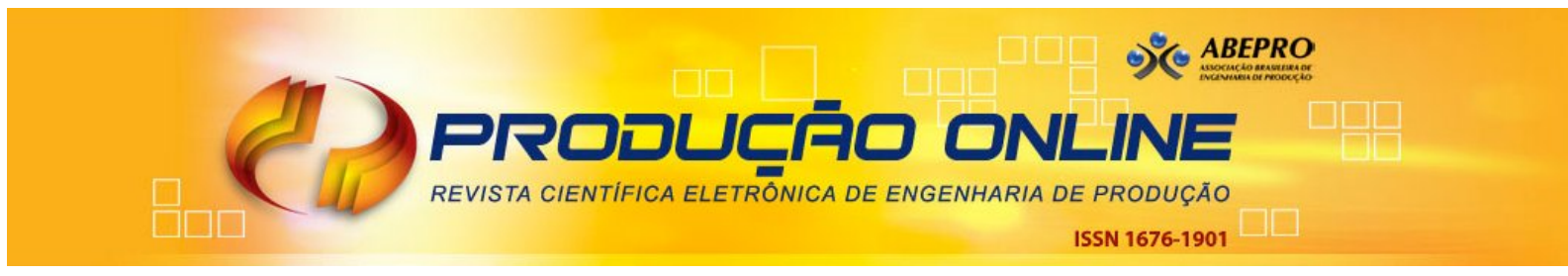

\title{
CARACTERÍSTICAS DE INDICADORES DE DESEMPENHO EM SISTEMAS DE INCENTIVO DO SETOR AUTOMOTIVO
}

\section{CHARACTERISTICS OF PERFORMANCE INDICATORS IN INCENTIVE SYSTEMS OF BRAZILIAN AUTOMOTIVE INDUSTRY}

\author{
Rosana Carmen de Meiroz Grillo Goncalves* E-mail: rosanagg@usp.br \\ Julia Peres Tortoli* E-mail:jptortoli@fearp.usp.br \\ *Faculdade de Economia, Administração e Contabilidade de Ribeirão Preto (FEARP-USP), Ribeirão \\ Preto, SP
}

\begin{abstract}
Resumo: Esta pesquisa visa obter respostas sobre quais indicadores de desempenho são utilizados pelas indústrias automotivas em seus sistemas de incentivo, ou seja, em seus acordos de participação nos lucros e resultados (PLR). Foram analisados 39 acordos de PLR, que tiveram seus indicadores de desempenho agrupados em seis classes: financeiros, qualidade, flexibilidade, produtividade, clientes e recursos humanos. Entre os resultados obtidos detectou-se a presença maciça de indicadores não-financeiros tradicionais, não tendo sido encontrados indicadores de desempenho mais voltados à inserção socioambiental da empresa, por exemplo, indicadores relacionados ao seu impacto ambiental. O predomínio de indicadores de produtividade e de qualidade remete à possibilidade do uso de indicadores não-financeiros como proxies de indicadores financeiros em ciclos econômicos em que há a expansão das atividades industriais. Após a exploração dos resultados, sugere-se que trabalhos futuros considerem o estudo da composição do grupo de indicadores juntamente com fatores que impactam a escolha dos indicadores, tais como posicionamento estratégico e sofisticação tecnológica.
\end{abstract}

Palavras-chaves: Sistemas de Mensuração de Desempenho. Indicadores de Desempenho. Sistemas de Incentivos. Mensuração de Desempenho. Setor Automotivo.

Abstract: This paper provides a general overview of the performance indicators used by Brazilian Automotive Industry in its profit sharing agreements, named PLR agreements. The 39 PLR agreements analyzed had their performance indicators classified in six groups: financial, quality, flexibility, productivity, customers and human resources. The results show a massive presence of traditional non-financial indicators, whereas performance indicators to cover social-environmental aspects have not been found. The predominance of indicators related to productivity and quality raised the possibility that in economic cycles with industry activity expansion, the non-financial indicators can be used as proxies of financial indicators. After analyzing the results, it was suggested that, in future, the study of the indicators basket should include its relations with strategic position, technological sophistication and other factors that impact the selection of indicators.

Keywords: Performance Measurement Systems. Performance Indicators. Incentive Systems. Performance Measurement. Automotive Industry. 


\section{INTRODUÇÃO}

A gestão baseada em avaliação de desempenho tradicionalmente apoia-se no princípio de que não se pode gerenciar aquilo que não é mensurado. Suas premissas incluem a necessidade de maior conhecimento sobre os processos de negócio e sobre como diferentes variáveis podem impactá-los. Assim, espera-se que a mensuração de desempenho oriente a progressão das organizações na consecução de seus planos de ação estratégicos, capacitando a harmonização dos objetivos de todos os atores organizacionais e também alavancando processos de aprendizagem organizacional.

A pesquisa em questão, em consonância com Chenhall (2007), toma como premissa que controles são necessários para encorajar gerentes e empregados de chão de fábrica a enfatizar aspectos críticos, os quais contribuem para o estabelecimento de vínculos importantes com toda a cadeia de valor. Este autor ressalta que os indicadores podem surgir tanto com a preocupação de se vincular processos a resultados estratégicos, como apenas com o objetivo de otimização local dos processos produtivos. No entanto, é fundamental que em qualquer abordagem de estudo haja a consideração das interdependências dos indicadores com o processo produtivo, incluindo o relacionamento com clientes, fornecedores e outras partes externas.

Ittner et al. (2003, p. 715) afirmam que a mensuração de desempenho "fornece informação financeira e não financeira, permitindo que a empresa identifique as estratégias, e potencialize a consecução de seus objetivos, alinhando seus processos de gestão". Primeiramente em Neely et al. (1995) e depois Tangem (2004), a mensuração de desempenho foi vinculada ao processo de quantificação da eficiência, eficácia e adaptabilidade das ações realizadas pelos que estão sendo avaliados.

Segundo Franco-Santos et al. (2012), a mensuração de desempenho possui resultados agrupados em três categorias: desempenho, competências organizacionais e influência no comportamento. $\mathrm{Na}$ primeira categoria estão os efeitos que levam a um desempenho superior que pode ser mensurado em diferentes níveis organizacionais. Quanto às competências organizacionais, alguns processos específicos incluídos na mensuração de desempenho podem levar a 
organização à obtenção de vantagens competitivas associadas ao alinhamento estratégico e à aprendizagem organizacional. Na terceira categoria, associada à influência no comportamento e aos incentivos, destaca-se que ações e reações relacionadas à motivação e à participação são causadas pela mensuração. Na perspectiva de Rosa et al. (2013) deve ser enfatizada a contribuição da mensuração de desempenho nos processos de tomada de decisão.

Este trabalho enquadra-se, portanto, na terceira categoria de Franco-Santos et al. (2012), uma vez que estuda indicadores de desempenho que visam o incentivo associado a impactos comportamentais. Seguindo esta linha, os indicadores de desempenho estudados são aqueles encontrados em acordos de participação nos lucros e resultados (PLR). Cabe destacar que os acordos de PLR são amplamente utilizados por indústrias brasileiras, possuindo regulamentação própria baseada na lei 10.101/2000, que apresenta a PLR como um instrumento de integração entre capital e trabalho e como um fator de incentivo à produtividade. Este estudo limita-se aos acordos firmados por indústrias do setor automotivo.

$\mathrm{Na}$ literatura internacional encontram-se várias pesquisas com foco nos indicadores de desempenho e no controle de gestão associados ao setor automotivo (MERCHANT; RICCABONI, 1990, VEEN-DIRKS, 2006, CARR et al., 2010; LI et al., 2013). Um estudo brasileiro, Kafrouni (2005), analisou a participação nos lucros e resultados como um sistema de trocas na indústria automobilística da Região Metropolitana de Curitiba, evidenciando impactos comportamentais associados a uma ampliação de funções do trabalhador. No entanto, há uma carência de estudos voltados à definição das cestas de indicadores que têm sido utilizadas, que possam também servir de referência na escolha futura de indicadores por outras indústrias.

Esta pesquisa restringe-se à caracterização dos indicadores de desempenho, considerando que o alcance das metas associadas a tais indicadores possibilita 0 recebimento de proventos por parte dos empregados como participação nos lucros e resultados. Pretende-se obter respostas sobre quais indicadores de desempenho são utilizados pelas indústrias do setor automotivo em seus sistemas de incentivo, ou seja, em seus acordos de participação nos lucros e resultados (PLR). A partir de tais respostas pretende-se enunciar hipóteses conclusivas sobre fatores que podem determinar a escolha de tais indicadores, que possam contribuir com a formação de premissas em estudos análogos. 


\section{REFERENCIAL TEÓRICO}

Como já mencionado, o trabalho de Franco-Santos et al. (2012) relaciona os sistemas de mensuração de desempenho (SMD) a três classes de impactos: (i) aumento do desempenho, (ii) alinhamento estratégico e (iii) incentivo. Segundo Grosswiele et al. (2013) é consensual o fato de que tais sistemas são instrumentos essenciais para o auxílio na tomada de decisões que levam a ações efetivas, corroborando com aumento de desempenho.

Woulters (2009) afirma que o impacto dos SMDs abrange tanto a formulação como a comunicação da estratégia. Wouters e Sportel (2005) afirmam que seu objetivo é dar suporte ao projeto e monitoração de iniciativas estratégicas. A definição e a atribuição de indicadores e metas são parte da formulação concreta das escolhas estratégicas. Kaplan e Norton (1992), ao descreverem o Balanced Scorecard, propuseram um SMD que apoiasse a tradução e a comunicação da estratégia e da visão adotadas pela empresa com seu desdobramento nos diferentes níveis organizacionais. Tal sistema deveria facilitar todo o planejamento de negócios, incluindo o alinhamento de iniciativas estratégicas, a fixação de metas, a alocação de recursos e o estabelecimento de marcos de controle. Ittner et al. (2003) também ressaltam que a mensuração de desempenho permite que a empresa identifique as estratégias e potencialize a consecução de seus objetivos com o alinhamento de seus processos de gestão.

Neste trabalho, assim como em Kennedy et al. (2009), os sistemas de incentivo são estudados como um tipo específico de sistema de controle de gestão, em que é fundamental a mensuração de desempenho. Para que um SMD esteja atrelado a incentivos é necessário que haja metas vinculadas a objetivos desdobrados a partir de estratégias organizacionais, sendo recompensadas ações que levem ao atingimento de tais metas e que conduzam à aprendizagem organizacional (SIMONS, 1994; 1995a; 1995b).

A ideia de incentivos atrelados aos sistemas de controle de gestão já havia sido proposta em Flamholtz (1979) e em Otley (1999). O controle de gestão é definido em Flamholtz (1979) como o processo de influenciar o comportamento dos membros de uma organização formal. Ele abrange uma série de mecanismos projetados para aumentar a probabilidade das pessoas se comportarem de modo a 
alcançar os objetivos da organização. Não se trata de controlar o comportamento das pessoas de maneira predeterminada, mas de fomentar o compartilhamento dos objetivos da organização e ações que estejam alinhadas com tais objetivos. Este autor estabelece que "o sistema de controle deve promover uma identidade entre os objetivos dos membros e da organização como um todo" (p. 182).

Em Otley (1999), um sistema de controle de gestão é definido como propiciador da congruência de objetivos. Para que seu projeto seja bem sucedido é necessária a definição de estratégias e seus desdobramentos, incluindo as atividades nas quais o desempenho será avaliado. É enfatizada a questão dos incentivos no âmago do controle de gestão, preconizando-se a definição de recompensas a gestores e a outros empregados.

Segundo Chong e Eggleton (2007), com o uso de sistemas de incentivo, as empresas buscam assegurar que os esforços dos empregados estarão voltados para atividades que facilitem o alcance dos objetivos organizacionais.

Os Subitens 2.1 e 2.2 tratam das dificuldades na definição de indicadores de desempenho adequados para a implementação de sistemas de incentivo, o que segundo Gibbs et al. (2009) talvez seja o maior desafio em seu projeto e implantação. Segundo tais autores, indicadores influenciados por fatores que os empregados não controlam, acarretam riscos aos empregados (Subitem 2.1.2). Por outro lado, uma ênfase excessiva em indicadores que reduzem risco pode levar a incentivos distorcidos.

\subsection{Dificuldades na operacionalização dos indicadores de desempenho}

Mesmo sendo observada a evolução de distintos sistemas de mensuração de desempenho, a dificuldade em se lidar com o universo dos indicadores ainda é muito vasta. Por ser um fenômeno que possui muitos aspectos, o desempenho organizacional acaba se tornando por muitas vezes complexo de se abordar (MACEDO e CORRAR, 2010).

Após a seleção de conceitos que devem ser monitorados, nem sempre é simples a definição da relação entre as dimensões teóricas do conceito e as variáveis operacionais. O conceito tem atributos ou dimensões teóricas, que definem "o que será medido". Já as variáveis operacionais definem 'como será medido'. O 
mapeamento do referencial conceitual em variáveis operacionais é um grande desafio. Quando se quer monitorar o desempenho do "controle de qualidade" de determinada fábrica, por exemplo, podem ser medidos os seguintes indicadores ou variáveis operacionais (surrogates ou proxies): 'tempo de espera pela rejeição ou aceitação da peça', 'tempo gasto com o teste de cada peça', 'índice de satisfação dos usuários com a qualidade das peças', etc.

Dado que este artigo ocupa-se da mensuração de desempenho no contexto de sistemas de incentivos, serão estudadas com destaque duas características das variáveis operacionais: congruência e ruídos.

\subsubsection{Medidas congruentes}

Segundo Zylberstajn (2002, p.247), os indicadores devem ser cuidadosamente escolhidos sob a pena de pagar-se pela performance dos trabalhadores, sem contudo, estarem sendo produzidos ganhos econômicos efetivos. Esse efeito é denominado distorção por Baker (2002).

Para minimizar distorções, devem-se ter medidas congruentes, ou seja, medidas que medem o progresso em direção ao atingimento dos objetivos da organização (MERCHANT; OTLEY, 2007). Segundo Kennerly e Neely (2003, p. 214), o desempenho é medido para a avaliação do sucesso da organização. Portanto, as enormes dificuldades desta área de estudo iniciam-se com a definição do que seria tal "sucesso", traduzido por Van Veen-Dirks (2010) como o aumento do valor da empresa. Esta autora define congruência como o grau em que as ações dos atores levam ao aumento do valor da empresa. Segundo a autora, a capacidade de elicitar ações que sejam congruentes com os objetivos é propriedade essencial da mensuração do desempenho.

Segundo Merchant (2006), o uso de medidas incongruentes pode motivar atos incorretos devido a um comportamento míope orientado pelo curto prazo.

Se for tomado como premissa que o objetivo que se superpõe aos demais é maximizar o valor da empresa e, por conseguinte o retorno dos acionistas, medidas de desempenho congruentes deveriam atrelar-se ao cálculo do retorno proporcionado aos acionistas. No entanto, tanto o valor da empresa como o retorno aos acionistas é difícil de ser medido. 
Testes de congruência têm mostrado uma baixa correlação entre o retorno proporcionado aos acionistas e indicadores contábeis tradicionais como resultado operacional, lucros e retorno sobre o capital investido (MERCHANT; OTLEY, 2007). Ressalta-se que o valor econômico agregado e o lucro econômico também não têm correlação comprovada com o retorno proporcionado aos acionistas (BIDDLE et al.,1997). Na ausência de tais medidas que apresentem correlação aceitável com o retorno proporcionado aos acionistas, há autores que propõem modelos com conjuntos de medidas, que incluam indicadores financeiros e não financeiros (WIDENER, 2006).

O modelo proposto por Baker (2002) afirma que quanto mais as medidas estiverem próximas aos níveis operacionais, possuindo, portanto, natureza não financeira, maiores distorções poderão causar. Organizações, particularmente as mais flexíveis, requerem que múltiplas tarefas sejam exercidas por uma única pessoa. No desempenho de suas funções, o indivíduo produzirá diferentes resultados, sendo alguns mais facilmente mensurados do que outros. É frequente o uso de sistemas de controle com indicadores de desempenho e metas vinculados às tarefas cujos outputs são de mais fácil mensuração. Segundo Van Veen-Dirks (2010), os atores alocarão esforços e recursos a várias tarefas baseando-se em quando esse procedimento afetará seus indicadores de desempenho que são importantes na determinação de recompensas. Isto pode causar um viés no indivíduo que passará a dedicar seus esforços de forma mais intensa às tarefas com resultados de mais fácil mensuração, prejudicando a organização ao desempenhar mediocremente outras tarefas relevantes, porém, de difícil mensuração. Assim, um conjunto de indicadores que causem distorções prejudicará a congruência.

\subsubsection{Medidas com ruído}

Indicadores de desempenho afetados por fatores que estão fora do controle do empregado são denominados de ruidosos (do inglês, noisy) (PRENDERGAST, 2002). Desta forma, independentemente de que o empregado faça, suas ações não serão as únicas determinantes do desempenho mensurado por tais indicadores. Baker (2002) contrapõe às distorções aos ruídos, deixando claro que a mensuração 
do valor da firma, indicador com menor distorção conceitual possível, pode acarretar ruídos expressivos.

O risco do empregado associa-se à sua exposição a variações que este não pode controlar. Um sistema de pagamento de incentivo baseado em medidas de desempenho com ruído submete a maiores riscos os avaliados. Quanto maior for o número de medidas com ruído, considerando que os empregados sejam avessos ao risco, maior insegurança será estabelecida. A escolha dos indicadores pode elicitar um trade-off entre oferecer incentivos e oferecer segurança. Segundo Gibbs et al. (2009), um bom indicador de desempenho representa a contribuição múltipla do empregado para a criação de valor da firma, sem impor-lhe um risco desnecessário.

Além disso, outro fator a ser considerado é a falta de entendimento (MERCHANT, 2006). Alguns indivíduos, além de expostos a variações incontroláveis, podem não entender o que devem fazer para agregar valor à organização.

\subsection{Conjuntos de indicadores de desempenho}

Hendriksen e Van Breda (1999) enfatizam que a mensuração do desempenho pode ser feita tanto sob a ótica de valores monetários, normalmente utilizando dados contábil-financeiros, como sob a ótica de informações não-monetárias, ou mesmo sob ambas perspectivas. Kaplan e Norton (1997) afirmam que apenas indicadores financeiros são inadequados para orientar e avaliar a trajetória da empresa. Tratamse de indicadores de ocorrência que levam em conta parte do efeito de ações passadas, não fornecendo orientações adequadas para as ações que devem ser realizadas visando a criação de valor financeiro futuro. Banker et al. (2000) argumentam que as medidas não-financeiras são melhores indicadores, trazendo informações mais adequadas sobre o desempenho futuro. A mensuração não financeira auxilia os gestores a focarem suas ações em perspectivas de longo prazo.

Vários autores, por exemplo: Kaplan e Norton (1992), Widener (2006), Merchant (2006), Van Veen-Dirks (2006) e Modell (2007), defendem o uso de conjunto de indicadores financeiros e não financeiros que possibilitem o controle de curto e de longo prazo. 
Embora Baker (2002) deixe clara a necessidade de maior pesquisa para esclarecer como devem ser combinadas as medidas ruidosas que aumentam o risco com medidas que trazem distorções, seu trabalho traz evidências que apontam para o uso de medidas múltiplas em sistemas de incentivo. Seu artigo mostra que mensurações trazidas por indicadores adicionais podem reduzir riscos à medida que não forem perfeitamente correlacionadas com o indicador anterior. É demonstrado que o uso de um segundo indicador reduz ruídos e distorções existentes comparando-se à utilização de apenas um indicador.

Ainda que a superioridade de sistemas com conjuntos ou cestas de indicadores financeiros e não financeiros seja difícil de ser comprovada com rigor empírico, tais conjuntos são facilmente encontrados, mostrando que as empresas acham neles alguma utilidade (MERCHANT, 2006).

\section{ASPECTOS METODOLÓgICOS}

Esta pesquisa foi realizada primordialmente mediante a análise de documentos de acordos coletivos de trabalho (ACTs), os quais trazem a descrição detalhada das regras para a participação nos lucros e resultados (PLR).

A regulamentação de acordos de PLR no Brasil baseia-se na lei 10.101/2000, que transformou a PLR em um direito que deve ser negociado entre a empresa e seus empregados com interveniência sindical. As implantações de acordos de PLR no setor automotivo foram pioneiras. Ainda que muitas indústrias interessem-se por tais acordos somente devido ao fato dos montantes distribuídos estarem isentos de contribuições previdenciárias obrigatórias, outras enxergam o PLR como instrumento de incentivo à produtividade.

A análise dos documentos com a descrição dos acordos de PLR fez-se mediante $\mathrm{o}$ isolamento das cláusulas que tratavam das metas e dos indicadores de desempenho propostos.

$\mathrm{Na}$ fase de exploração do material, foram destacados indicadores de desempenho corporativos e setoriais, juntamente com indicadores usados como gatilho. Os indicadores-gatilho, quando superados, implicam na aplicação de outros indicadores para o cálculo dos montantes a serem distribuídos, e quando não superados, inibem a distribuição da PLR. Após o destaque dos indicadores foram Revista Produção Online, Florianópolis, SC, v.15, n. 3, p. 999-1020, jul./set. 2015. 
realizados os procedimentos de categorização conforme o quadro referencial da pesquisa (Item 3.2).

Em etapa posterior à composição da amostra de documentos a serem analisados, foram recuperados dados referentes ao faturamento e a atuação mercadológica das empresas na Revista Exame-Maiores e Melhores, em outras revistas de negócio e em seus respectivos sites.

\subsection{Definição da amostra}

Para a composição de uma amostra, que represente significativamente o setor automotivo, foram selecionadas as empresas que possuem as atividades principais designadas pelos códigos de atividades econômicas (CNAEs) apresentados no Quadro 1.

Houve um interesse explícito de que a amostra contemplasse as empresas com maior faturamento, para tanto, foi incluída a totalidade das empresas com os CNAEs selecionados, provenientes de três fontes: (a) conjunto de empresas no site da Revista Exame - Maiores e Melhores (REVISTA EXAME, 2011); (b) conjunto de empresas de capital aberto listadas na CVM- Comissão de Valores Mobiliários; (c) empresas associadas à Associação Nacional dos Fabricantes de Veículos Automotores (ANFAVEA).

Quadro 1 - Atividades econômicas das indústrias que compõem a amostra

\begin{tabular}{|l|l|}
\hline CNAE & \multicolumn{1}{|c|}{ Descrição } \\
\hline 28 & Fabricação de Máquinas e Equipamentos \\
28.3 & Fabricação de Tratores e de Máquinas e Equipamentos para a Agricultura e Pecuária \\
29 & Fabricação de Veículos Automotores, Reboques e Carrocerias \\
29.1 & Fabricação de Automóveis, Camionetas e Utilitários \\
29.2 & Fabricação de Caminhões e Ônibus \\
29.3 & Fabricação de Cabines, Carrocerias e Reboques para Veículos Automotores \\
29.4 & Fabricação de Peças e Acessórios para Veículos Automotores \\
29.5 & Recondicionamento e Recuperação de Motores para Veículos Automotores \\
30 & Fabricação de outros Equipamentos de Transporte, exceto Veículos Automotores \\
30.1 & Construção de Embarcações \\
30.3 & Fabricação de Veículos Ferroviários \\
30.4 & Fabricação de Aeronaves \\
30.5 & Fabricação de Veículos Militares de Combate \\
30.9 & Fabricação de Equipamentos de Transporte não especificados anteriormente \\
30.9 .1 & Fabricação de Motocicletas \\
\hline
\end{tabular}

Fonte: adaptado do IBGE, disponível em <http://www.cnae.ibge.gov.br>. 
Por meio dessa coleta, foram obtidas 94 empresas, representando o setor automotivo. Os documentos que abrangem a descrição dos acordos de participação nos lucros ou resultados (PLRs) foram coletados no sítio eletrônico do Ministério do Trabalho e Emprego (MTE), por meio do sistema Mediador.

Por meio dos CNPJs disponíveis relativos as 94 empresas, a procura dos acordos de PLR no site do MTE, teve resultado positivo para 52 delas (55\% das empresas). Em tais acordos, os conteúdos variaram desde a menção de negociação à descrição completa das regras para a PLR.

Dentre os 52 acordos de PLR foram excluídos treze documentos que não traziam os dados necessários ou que estabeleciam quantias fixas, restando para a análise documental 39 acordos de PLR.

\subsection{Quadro referencial da pesquisa}

O quadro de referência desta pesquisa propõe o agrupamento dos indicadores em financeiros e não-financeiros, sendo que os últimos formam cinco categorias: (i) qualidade; (ii) flexibilidade; (iii) produtividade; (iv) clientes; e (v) recursos humanos.

Este agrupamento foi testado com sucesso na classificação dos 23 indicadores de desempenho usados em Van Veen-Dirks (2010), que por sua vez traduziam a compilação de indicadores de desempenho usados por outros autores. Enfatiza-se que a classificação não é definitiva, frente à possibilidade eminente de surgimentos de indicadores inclassificáveis.

Os indicadores financeiros além daqueles expressos em moeda corrente (faturamento, lucro líquido etc.) também incluem aqueles expressos na forma de quocientes ou razões cujos numeradores ou denominadores são números contábeis bem definidos. Exemplos de tais indicadores são ROI, ROE, custo efetivo/custo padrão etc. Nesta classe também se inclui o índice de rotação de estoque, quando expresso pelo custo das mercadorias vendidas dividido pelo valor médio do estoque.

O grupo de indicadores de qualidade inclui tanto indicadores que medem a quantidade de produtos aprovados no controle de qualidade, como indicadores que se associam à falta de qualidade: percentagem de produtos com defeitos, número de produtos devolvidos ou encaminhados à assistência técnica. Também se 
enquadram neste grupo outros indicadores associados a auditorias de qualidade e aos movimentos de qualidade total, que implicam na mensuração de métricas como limpeza e organização, entre outras.

O grupo de indicadores voltados à flexibilidade compreende os indicadores voltados a medir a flexibilidade na produção, mediante diferentes possibilidades de reconfiguração das linhas de produção, ou à mensuração dos tempos de mudança de produção de diferentes produtos, e de diferentes famílias de produtos. Flexibilidade também pode significar aumento do portfólio de produtos mediante o lançamento de novos produtos ou mediante variações feitas nas características de produtos existentes. Também tem sido medida a flexibilidade nos setores voltados a atender os clientes, quer mediante a mensuração do tempo de atendimento de diferentes tipos de pedidos, ou do tempo de atendimento de pedidos de modificações feitas pelos clientes.

No grupo de indicadores de produtividade incluem-se à mensuração dos tempos de set up, e de outros tempos com máquinas paradas devido a problemas técnicos, ou a falta de insumos. Também incluem indicadores relacionados à eficiência no uso dos insumos, que implicam na mensuração de perdas na produção (refugos ou sucatas). São comuns neste grupo indicadores voltados ao controle da produtividade da mão-de-obra direta, em geral, medida pela razão entre horas efetivas e horas padrão, e pela frequência de rotinas de retrabalho.

Indicadores associados aos clientes podem implicar na mensuração da participação de mercado desdobrada ao ponto de monitorarem-se índices de vendas para grupos específicos de clientes e também em mensurações da satisfação do cliente, e de sua captação e retenção. Exemplos de indicadores voltados à mensuração da satisfação são: número de reclamações recebidas, pesquisas de satisfação dos clientes com produtos e com assistência técnica.

No grupo de indicadores associados aos recursos humanos (WIDENER, 2006) incluem-se: índices de cooperação intra-equipes, satisfação dos empregados, rotatividade de empregados, número de acidentes de trabalho, número de empregados treinados e satisfação dos clientes internos. 


\section{ANÁLISE DOS RESULTADOS}

Uma tipificação resumida dos acordos estudados mostra que apenas seis deles tinham uma cesta de indicadores com sete ou mais indicadores, sendo a que a maior cesta contém pelo menos dezenove indicadores. Cerca de 64\% dos acordos possuíam cestas com até quatro indicadores (uma apresentação completa dos indicadores da amostra encontra-se no Apêndice 1).

Apenas três acordos possuem indicadores somente financeiros e 23 empresas somente indicadores não financeiros, sendo que as demais (treze empresas) possuem cestas com indicadores de ambas categorias. Tais resultados divergem das pesquisas que preconizam a prevalências de indicadores de desempenho financeiro. Observa-se, no entanto, que tais pesquisas, em sua maioria, analisam indicadores de desempenho utilizados para oferecer incentivos a executivos. Praticamente a totalidade dos acordos de PLR examinados destinava-se a oferecer incentivos universalmente a todos os empregados da indústria: dos gestores aos operários do chão de fábrica, incluindo os empregados de setores administrativos. Uma vez que a maioria dos candidatos a receberem os incentivos entende melhor os indicadores não-financeiros, talvez isso possa justificar a prevalência de tais indicadores.

Os indicadores-gatilho classificados como financeiros foram encontrados em cerca de $15 \%$ dos acordos, e classificados como não-financeiros foram encontrados em cerca de 34\% dos acordos; as demais empresas não possuíam indicadoresgatilho. Com isso, percebe-se a clara preferência por indicadores não-financeiros como condicionamento do pagamento de PLR.

De acordo com os dados do Quadro 2, os 39 acordos de PLR analisados apresentaram indicadores em diferentes categorias de agrupamento com ênfase para indicadores voltados à mensuração da produtividade, presentes em $82 \%$ dos acordos. A mensuração da qualidade esteve presente em 56\% dos acordos. Já indicadores financeiros estiveram presentes em $41 \%$ dos acordos. Os indicadores menos presentes nos acordos foram: clientes (36\%), recursos humanos (36\%) e flexibilidade (15\%). 
Quadro 2 - Percentual de Acordos de PLR com inclusão de indicadores por categoria

\begin{tabular}{|r|c|}
\hline Classe de Indicadores & Frequência \\
\hline Produtividade & $82 \%$ \\
Qualidade & $56 \%$ \\
Financeiros & $41 \%$ \\
Clientes & $36 \%$ \\
Recursos Humanos & $36 \%$ \\
Flexibilidade & $15 \%$ \\
\hline
\end{tabular}

Fonte: Autores

Analisando-se as catorze empresas que possuíam em seus acordos indicadores de desempenho voltados aos clientes, verificou-se que todas elas, montadoras ou indústrias de autopeças, eram líderes de mercado em alguns de seus produtos ou famílias de produtos. Tal fato pode sugerir um uso de indicadores estratégicos de desempenho também nos sistemas de incentivo.

$\mathrm{Na}$ análise das cestas de indicadores foram usados três grupos: (i) conjunto de indicadores apenas financeiros, (ii) conjunto de indicadores exclusivamente nãofinanceiros e (ii) conjuntos de indicadores mistos. Analisando-se o percentual de empresas com acordos que pertencem a cada um desses tipos, também prevalecem empresas ou acordos que dão preferência ao uso exclusivo de indicadores nãofinanceiros (59\% da amostra).As cestas com indicadores mistos estão presentes em $33 \%$ das empresas ou acordos. Ressalta-se que $77 \%$ das empresas que possuem cestas com conjuntos mistos de indicadores são montadoras, e apenas $23 \%$ das empresas são fabricantes de autopeças. Levando-se em conta as afirmações do referencial bibliográfico que reportam conjuntos mistos como mais adequados, esses dados podem sugerir que as montadoras têm melhores conjuntos de indicadores do que as fábricas de autopeças.

\section{CONCLUSÃO}

Foram obtidas respostas quanto ao número e às categorias de indicadores utilizados por uma amostra de empresas do setor automotivo em seus acordos de participação nos lucros e resultados.

Revista Produção Online, Florianópolis, SC, v.15, n. 3, p. 999-1020, jul./set. 2015. 
Os indicadores-gatilho relacionados a indicadores financeiros foram surpreendentemente encontrados em apenas cerca de $15 \%$ dos acordos. Houve, no entanto, um maior número de indicadores-gatilho relacionados ao número de veículos produzidos (em 34\% dos acordos).

Foi maciça a presença de indicadores não-financeiros tradicionais. Ainda que a absoluta maioria das empresas possua diferentes certificações ambientais (ISO 14001 e outras), não foram encontrados indicadores de desempenho mais voltados à inserção socioambiental da empresa, ou ao impacto ambiental, como por exemplo índices de consumo de água ou de emissões atmosféricas.

O uso excessivo de indicadores não-financeiros permite a enunciação de algumas hipóteses conclusivas que possam ser verificadas em pesquisas futuras. A primeira afirma que em mercados aquecidos, indicadores não-financeiros podem estar altamente correlacionados com indicadores financeiros relacionados às vendas, sendo utilizados como suas proxies. Quantidade produzida, por exemplo, pode ser tomada como proxy de receitas de vendas. Pode-se afirmar também que o uso excessivo de indicadores não-financeiros é explicado pela capacidade de entendimento dos indivíduos avaliados, dado que a literatura afirma serem de mais fácil entendimento os indicadores não-financeiros.

Por fim, pode enunciar-se a premissa de que o papel dos atores na definição dos indicadores de desempenho pode ser mais relevante do que sua qualidade intrínseca, ou seja, do que a acuidade e congruência do indicador propriamente dito. Houve clara preferência por indicadores não-financeiros mais facilmente controláveis e que reduzem o risco dos avaliados. Sabe-se que, no Brasil, a posição dos sindicatos na negociação de acordos de PLR sempre foi direcionada à redução de riscos, existindo inúmeros acordos, particularmente, os efetuados por meio de Convenção Coletiva, em que são estabelecidos valores fixos a serem distribuídos a título de PLR. Portanto, além das considerações de fatores que tipicamente podem implicar na escolha de indicadores: estratégias, sofisticação tecnológica, etc. também parece ganhar relevância o estudo da composição do grupo negociador que efetiva a escolha dos indicadores.

O fato de que todas as empresas com indicadores de desempenho voltados aos clientes serem líderes de mercado, faz com que seja relevante um estudo 
posterior levando em conta as posições estratégicas diversas das organizações, ao se escolher os indicadores.

Sugere-se, portanto, que estudos futuros levem em consideração a relação de fatores que impactam na escolha dos indicadores de desempenho, tais como: posicionamento estratégico, sofisticação tecnológica e composição do grupo negociador. Além disso, recomenda-se que seja aumentado o número de acordos de PLR passíveis de análise, assim como sejam utilizados diferentes testes estatísticos de confiança para análise dos resultados obtidos.

\section{REFERÊNCIAS}

BAKER, G. Distortion and Risk in Optimal Incentive Contracts. Journal of Human Resources, v. 37, n. 4, p.728-751, 2002.

BANKER, R. D.; POTTER, G.; SRINIVASAN, D. An empirical investigation of an incentive plan that includes nonfinancial performance measures. The Accounting Review 75(1): 6592, 2000.

BIDDLE, G. C.; BOWEN, R. M.; WALLACE, J. S. Does EVA beat earnings? Evidence on the association with stock returns and financial values. Journal of Accounting and Economics, v. 24, p.301-336, 1997.

CARR, C. et al. Strategic investment decision making practices: A contextual approach. Management Accounting Research, v. 21, p.167-184, 2010.

CHENHALL, R. H. Theorizing Contingencies in Management Control Systems Research. In CHAPMAN, C; HOPWOOD, A.; SHIELDS, M. Handbook of Management Accounting Research, v. 2. Elsevier, 2007.

CHONG, V. K.; EGGLETON, I. R. C. The impact of reliance on incentive-based compensation schemes, information asymmetry and organizational commitment on managerial performance. Management Accounting Research, v. 18, n. 3, p. 312-342, 2007.

FLAMHOLTZ, E. G. Organizational control systems as managerial tool. California Management Review, Berkeley, v. 22, n. 2, p. 50-60, winter, 1979.

FRANCO-SANTOS, M. et al. Contemporary performance measurement systems: a review of their consequences and a framework for research. Management Accounting Research. v. 23, n. 2, p. 79-119, 2012. http://dx.doi.org/10.1016/j.mar.2012.04.001

GIBBS, M. J. et al. Performance Measure Properties and Incentive System Design. Industrial Relations: A Journal of Economy and Society, v. 48, n. 2, p. 237-264, 2009.

GROSSWIELE, L.; RÖGLINGER, M.; FRIEDL, B. A decision framework for the consolidation of performance measurement systems. Decision Support Systems, v. 54, n. 2, p. 10161029, 2013.

Revista Produção Online, Florianópolis, SC, v.15, n. 3, p. 999-1020, jul./set. 2015. 
HENDRIKSEN, E. S.; VAN BREDA, M. F. Teoria da Contabilidade. São Paulo: Atlas, 1999. HESFORD, J. W. et al. Management Accounting: A Bibliographic Study. In:

CHAPMAN, C; HOPWOOD, A.; SHIELDS, M. Handbook of Management Accounting Research, v. 1. Elsevier, 2007.

IBGE, Instituto Brasileiro de Geografia e Estatística. Disponível em:

$<$ http://www.cnae.ibge.gov.br>. Acesso em: mar/2012.

ITTNER, C. D.; LARCKER, D. F. Coming up short on nonfinancial performance measurement. Harvard Business Review, v. 81, n. 11, p. 88-95, 2003.

ITTNER, C.D.; LARCKER, D.F.; RANDALL, T. Performance implications of strategic performance measurement in financial service firms. Accounting, Organizations and Society, v.28, n.8, p. 715-741, 2003.

KAFROUNI, M. A. S. A participação nos lucros e resultados na indústria automobilística do Paraná: um sistema de trocas para além das mercadorias. Tese de Mestrado em Sociologia. Universidade Federal do Paraná. Curitiba, 2005.

KAPLAN, R. S.; NORTON, D. P. The Balanced Scorecard - The measures that drive performance. The Harvard Business Review, January-February, 12 p.,1992.

KAPLAN, R. S.; NORTON, D.P. Estratégiaemação: Balanced Scorecard. 9a ed. Rio de Janeiro: Campus, 344 p., 1997.

KENNERLY, M.; NEELY, A. Measuring performance in a changing business environment. International Journal of Operations \& Production Management, v. 23, n. 2, p. 213-229, 2003.

KENNEDY, F. A., et al. The roles of organizational justice and trust in a gain-sharing control system. Advances in Accounting Behavioral Research, v. 12, p.1-23, 2009.

$\mathrm{LI}$, P. et al. The characteristics and dynamics of management controls in IJVs: Evidence from a Sino-Japanese case. Management Accounting Research, v. 24, p. 246-260, 2013. http://dx.doi.org/10.1016/j.mar.2013.04.002

MACEDO, M. A. S.; CORRAR, L. J. Análise do Desempenho Contábil-Financeiro de Seguradoras no Brasil no ano de 2007: um estudo apoiado em Análise Hierárquica (AHP). Contabilidade Vista \& Revista, v. 21, n. 3, p. 135-165, 2010

MERCHANT, K. A.; RICCABONI, A. Performance-based management incentives at the Fiat Group: a field study. Management Accounting Research, v. 1, p. 281-303, 1990.

MERCHANT, K. A. Measuring general managers' performances: Market, accounting and combination-of-measures systems. Accounting, Auditing \& Accountability Journal v. 19, n.6, p. 893-917, 2006.

MERCHANT, K. A.; OTLEY, D. A Review of the literature on control and accountability. In CHAPMAN, C; HOPWOOD, A.; SHIELDS, M. Handbook of Management Accounting Research, v. 2. Elsevier, 2007.

MODELL, S. Managing accounting change. In HOPPER, T. el al (orgs.). Issues in Management Accounting, 3th Edition, Prentice Hall, 2007. 
NEELY, A.; et al. Performance measurement system design: a literature review and research agenda. International Journal of Operations \& Production Management, v. 15, n. 4, p. 81-116, 1995.

OTLEY, D. T. Performance management: a framework for management control systems research. Management Accounting Research, v. 10, n. 4, p. 363-382, 1999.

PRENDERGAST , C. Uncertainty and Incentives. Journal of Labor Economics, v. 20, n. 2, p. 115-137, 2002.

REVISTA EXAME- Maiores e Melhores Empresas do Brasil, 2011. Disponível em: http://exame.abril.com.br/negocios/melhores-e-maiores/>. Acesso em: mar/2012.

ROSA, F. S.; ENSSLIN, S. R.; ENSSLIN, L. Avaliação de Desempenho: processo de revisão sistêmica de literatura internacional. Revista Produção Online, v.13, n. 2, p. 390-416, 2013. http://dx.doi.org/10.14488/1676-1901.v13i2.806

SIMONS, R. How top managers use control systems as levers of strategic renewal.

Strategic Management Journal, v. 15, p. 169-189, 1994.

SIMONS, R. Control in an age of empowerment. Harvard Business Review, v. 67, n. 2, p. 80-88, 1995a.

SIMONS, R. Levers of Control: How Managers Use Innovative Control Systems to Drive Strategic Renewal. Harvard Business School Press, 1995b.

TANGEN, S. Performance measurement: from philosophy to practice. International Journal of Operations \& Production Management, v. 53, n. 8, p. 726-737, 2004.

VAN VEEN-DIRKS, P. Complementary choices and management control: Field research in a flexible production environment. Management Accounting Research, v.17, p.72-105, 2006.

VAN VEEN-DIRKS, P. Different uses of performance measures: The evaluation versus reward of production managers. Accounting, Organizations and Society, v. 35, n. 2, p. 141-164, 2010.

WIDENER, S. K. Human capital, pay structure, and the use of performance measures in bonus compensation, Management Accounting Research, v.17, p. 198-221, 2006.

WOUTERS, M. A developmental approach to performance measures-Results from a longitudinal case study. European Management Journal, v. 27, n. 1, p. 64-78, 2009.

WOUTERS, M. \& SPORTEL, M. The role of existing measures in developing and implementing performance measurement systems. International Journal of Operations \& Production Management, v. 25, n. 11, p. 1062-1082, 2005.

ZYLBERSTAJN, H. The Brazilian case: performance pay as worker's right. In BROWN, M.; HEYWOOD, J. S. Paying for performance, an international comparison. M. E. Sharp, p. 236-260, 2002.

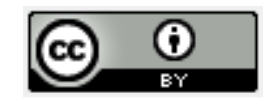

Artigo recebido em 07/12/2014 e aceito para publicação em 11/12/2014 DOI: http://dx.doi.org/ 10.14488/1676-1901.v15i3.1946 


\begin{tabular}{|c|c|c|c|c|c|c|}
\hline $\begin{array}{c}\text { ACORDO DE PARTICIPAÇÃO NOS } \\
\text { LUCROS E RESULTADOS POR } \\
\text { EMPRESA }\end{array}$ & FINANCEIROS & QUALIDADE & $\begin{array}{l}\text { FLEXIBILIDADE E } \\
\text { CICLOS }\end{array}$ & PRODUTIVIDADE & CLIENTES & $\begin{array}{l}\text { RECURSOS } \\
\text { HUMANOS }\end{array}$ \\
\hline 1 & - & $\begin{array}{l}\text { Nota da Auditoria, } \\
\text { Índice de Qualidade }\end{array}$ & - & $\begin{array}{l}\text { Produtividade, Tempo } \\
\text { despendido na produção } \\
\text { por carro }\end{array}$ & - & Absenteísmo Coletivo \\
\hline 2 & 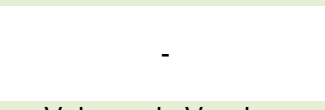 & $\begin{array}{l}\text { Índice de Organização, } \\
\text { Limpeza e Arrumação }\end{array}$ & $\begin{array}{l}\text { Vida útil de } \\
\text { Equipamento na } \\
\text { Produção }\end{array}$ & $\begin{array}{l}\text { Refugo, Tempo de Set-up, } \\
\text { Insumos, Produtividade }\end{array}$ & $\begin{array}{l}\text { Índice de } \\
\text { Devoluções }\end{array}$ & $\begin{array}{l}\text { Número de Acidentes de } \\
\text { Trabalho, Número de } \\
\text { Incidentes }\end{array}$ \\
\hline 3 & $\begin{array}{l}\text { Volume de Vendas, } \\
\text { Gastos Gerais de } \\
\text { Fabricação, Redução de } \\
\text { Compras, Resultado } \\
\text { Operacional Mínimo }\end{array}$ & - & - & Refugo & $\begin{array}{c}\text { Número de } \\
\text { Reclamações }\end{array}$ & Segurança no Trabalho \\
\hline 4 & $\begin{array}{l}\text { Resultado Operacional } \\
\text { Mínimo, Faturamento }\end{array}$ & Auditoria por Produto & - & $\begin{array}{l}\text { Retrabalho, Sucata, } \\
\text { Produtividade }\end{array}$ & $\begin{array}{l}\text { Índice de } \\
\text { Satisfação }\end{array}$ & - \\
\hline 5 & $\begin{array}{l}\text { Retorno sobre Ativos, } \\
\text { Valor Adicionado ao } \\
\text { Acionista, Resultado } \\
\text { Econômico Global }\end{array}$ & - & $\begin{array}{c}\text { Tempo de Entrega do } \\
\text { Produto }\end{array}$ & $\begin{array}{l}\text { Produtividade, Tempo } \\
\text { despendido na produção } \\
\text { por carro }\end{array}$ & - & - \\
\hline 6 & Faturamento & - & - & - & - & - \\
\hline 7 & $\begin{array}{l}\text { Gastos com serviços } \\
\text { terceirizados; Custo das } \\
\text { sobras (scrap) }\end{array}$ & Auditoria de qualidade & $\begin{array}{l}\text { Cobertura do estoque } \\
\text { em } \\
\text { dias(inventorydayssup } \\
\text { ply) }\end{array}$ & $\begin{array}{l}\text { Tempo despendido para a } \\
\text { produção de um carro } \\
\text { Perdas na Produção, } \\
\text { Número de Reparos por } \\
\text { mil veículos }\end{array}$ & - & $\begin{array}{l}\text { No Acidentes, } \\
\text { Absenteísmo; } \\
\text { Participação em } \\
\text { treinamentos }\end{array}$ \\
\hline 8 & - & Auditoria de qualidade & - & $\begin{array}{l}\text { Produtividade, Tempo } \\
\text { despendido para a } \\
\text { produção de um carro }\end{array}$ & - & Absenteísmo Coletivo \\
\hline 9 & - & $\begin{array}{c}\text { Índice Técnico de } \\
\text { Qualidade }\end{array}$ & - & $\begin{array}{l}\text { Produtividade, Tempo } \\
\text { despendido na produção } \\
\text { por carro }\end{array}$ & - & - \\
\hline 10 & - & $\begin{array}{l}\text { Índice de Rejeição de } \\
\text { Produtos, Índice de } \\
\text { Organização, Limpeza } \\
\text { e Arrumação }\end{array}$ & $\begin{array}{c}\text { Tempo de Entrega do } \\
\text { Produto }\end{array}$ & ${ }^{-1}$ & - & - \\
\hline 11 & Lucro Líquido & - & - & Geração de Sucata & - & $\begin{array}{c}\text { Número de Acidentes de } \\
\text { Trabalho }\end{array}$ \\
\hline
\end{tabular}

Fonte: Autores 
Apêndice 2- Descrição dos Indicadores em cada Acordo de Participação nos Lucros e Resultados

\begin{tabular}{|c|c|c|c|c|c|c|}
\hline $\begin{array}{c}\text { ACORDO DE PARTICIPAÇÃO NOS } \\
\text { LUCROS E RESULTADOS POR } \\
\text { EMPRESA }\end{array}$ & FINANCEIROS & QUALIDADE & $\begin{array}{l}\text { FLEXIBILIDADE E } \\
\text { CICLOS }\end{array}$ & PRODUTIVIDADE & CLIENTES & RECURSOS HUMANOS \\
\hline 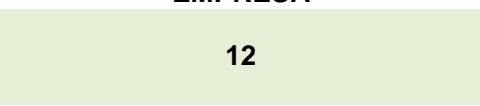 & - & $\begin{array}{l}\text { Peças Devolvidas } \\
\text { pelo Controle de } \\
\text { Qualidade }\end{array}$ & - & $\begin{array}{l}\text { Produtividade, Refugo, } \\
\text { Inventários }\end{array}$ & - & - \\
\hline 13 & - & $\begin{array}{l}\text { Programa de } \\
\text { Melhorias, Auditoria } \\
5 \mathrm{~S},\end{array}$ & - & $\begin{array}{c}\text { Produtividade, Perdas, } \\
\text { Refugos }\end{array}$ & - & $\begin{array}{c}\text { Número de Acidentes de } \\
\text { Trabalho }\end{array}$ \\
\hline 14 & - & $\begin{array}{l}\text { Índice de Qualidade } \\
\text { sob a ótica do } \\
\text { Cliente }\end{array}$ & - & Produtividade & $\begin{array}{l}\text { Índice de } \\
\text { Satisfação }\end{array}$ & Absenteísmo Coletivo \\
\hline 15 & - & Índice de Qualidade & - & Produtividade & $\begin{array}{c}\text { Número de } \\
\text { Reclamações }\end{array}$ & - \\
\hline 16 & - & $\begin{array}{l}\text { Índice de Rejeição } \\
\text { da Linha de } \\
\text { Montagem }\end{array}$ & - & $\begin{array}{l}\text { Cumprimento do Plano de } \\
\text { Produção }\end{array}$ & - & $\begin{array}{c}\text { Número de Acidentes de } \\
\text { Trabalho }\end{array}$ \\
\hline 17 & $\begin{array}{l}\text { Participação de } \\
\text { Mercado }\end{array}$ & $=0$ & - & - & $\begin{array}{l}\text { Índice de } \\
\text { Satisfação }\end{array}$ & - \\
\hline 18 & $\begin{array}{l}\text { Participação de } \\
\text { Mercado }\end{array}$ & $\begin{array}{c}\text { Índice de Rejeição } \\
\text { de Motores }\end{array}$ & - & Produtividade & $\begin{array}{l}\text { Índice de } \\
\text { Satisfação }\end{array}$ & - \\
\hline 19 & Liderança de Mercado & - & - & Produtividade & - & - \\
\hline 20 & $\begin{array}{c}\text { Despesas com Vendas, } \\
\text { Gerais e Administrativas } \\
\text { (SG\&A) }\end{array}$ & Produtos Devolvidos & - & $\begin{array}{c}\text { Sucatas, Produtividade, } \\
\text { Inventários }\end{array}$ & - & - \\
\hline 21 & $x$ & $\begin{array}{l}\text { Programa de } \\
\text { Melhorias }\end{array}$ & - & Refugo & $\begin{array}{c}\text { Número de } \\
\text { Reclamações }\end{array}$ & - \\
\hline 22 & - & - & - & Refugo, Produtividade & - & - \\
\hline 23 & - & $\begin{array}{l}\text { Nota em Auditoria } \\
\text { de Processo }\end{array}$ & - & Produtividade & - & - \\
\hline 24 & Faturamento & - & - & - & - & - \\
\hline 25 & - & $\begin{array}{c}\text { Índice de Qualidade } \\
\text { no pré-delivery }\end{array}$ & - & $\begin{array}{l}\text { Produtividade, Tempo } \\
\text { despendido na produção } \\
\text { por carro }\end{array}$ & - & $\begin{array}{l}\text { Segurança no Trabalho, } \\
\text { Absenteísmo Coletivo }\end{array}$ \\
\hline
\end{tabular}

Fonte: Autores 
Apêndice 3- Descrição dos Indicadores em cada Acordo de Participação nos Lucros e Resultados

(continuação)

\begin{tabular}{|c|c|c|c|c|c|c|}
\hline $\begin{array}{c}\text { ACORDO DE PARTICIPAÇAO NOS } \\
\text { LUCROS E RESULTADOS POR } \\
\text { EMPRESA }\end{array}$ & FINANCEIROS & QUALIDADE & $\begin{array}{l}\text { FLEXIBILIDADE E } \\
\text { CICLOS }\end{array}$ & PRODUTIVIDADE & CLIENTES & RECURSOS HUMANOS \\
\hline ( & - & $\begin{array}{l}\text { Índice de Qualidade } \\
\text { no pré-delivery, } \\
\text { Indicadores de } \\
\text { Qualidade no } \\
\text { Campo de Prova, } \\
\text { Indicadores de } \\
\text { Qualidade em } \\
\text { Laboratório }\end{array}$ & - & $\begin{array}{l}\text { Índice de Produtividade, } \\
\text { índice de Retrabalho }\end{array}$ & - & Número de acidentes \\
\hline 27 & - & $\begin{array}{l}\text { Índice de Qualidade } \\
\text { no pré-delivery, } \\
\text { Indicadores de } \\
\text { Qualidade no } \\
\text { Campo de Prova, } \\
\text { Indicadores de } \\
\text { Qualidade em } \\
\text { Laboratório }\end{array}$ & - & Produtividade & - & Segurança no Trabalho \\
\hline 28 & - & $\begin{array}{l}\text { Índice de Qualidade } \\
\text { no pré-delivery, } \\
\text { Indicadores de } \\
\text { Qualidade no } \\
\text { Campo de Prova, } \\
\text { Indicadores de } \\
\text { Qualidade em } \\
\text { Laboratório }\end{array}$ & - & $\begin{array}{l}\text { Produtividade e índices de } \\
\text { Eliminação de } \\
\text { Desperdícios }\end{array}$ & - & $\begin{array}{l}\text { Número de Acidentes de } \\
\text { Trabalho, Número de } \\
\text { Incidentes }\end{array}$ \\
\hline 29 & $\begin{array}{c}\text { Resultado Operacional, } \\
\text { Fluxo de Caixa, } \\
\text { Faturamento, } \\
\text { Participação de } \\
\text { Mercado (nacional e } \\
\text { internacional), Lucro e } \\
\text { Margem Operacional, } \\
\text { Redução do Custo do } \\
\text { Produto, Gastos com } \\
\text { garantia em relação ao } \\
\text { faturamento,Valor do } \\
\text { estoque médio anual } \\
\text { mantido nas fábricas }\end{array}$ & $\begin{array}{l}\text { Indicadores do } \\
\text { Prêmio Nacional de } \\
\text { Qualidade, Média de } \\
\text { Falhas por veículo, } \\
\text { Auditoria por } \\
\text { Produto, Tempo } \\
\text { médio para } \\
\text { resolução de } \\
\text { problemas de } \\
\text { qualidade }\end{array}$ & $\begin{array}{c}\text { Leadtime das } \\
\text { unidades faturadas, } \\
\text { Tempo Médio para } \\
\text { resolução de } \\
\text { problemas em campo, } \\
\text { Aumento no prazo de } \\
\text { pagamento médio de } \\
\text { fornecedores, } \\
\% \text { de atividades de } \\
\text { projetos entregues no } \\
\text { prazo }\end{array}$ & Produtividade & $\begin{array}{l}\text { Satisfação dos } \\
\text { Clientes com } \\
\text { entrega de } \\
\text { produtos e com } \\
\text { serviços }\end{array}$ & - \\
\hline
\end{tabular}

Fonte: Autores 
Apêndice 4- Descrição dos Indicadores em cada Acordo de Participação nos Lucros e Resultados

(conclusão)

\begin{tabular}{|c|c|c|c|c|c|c|}
\hline $\begin{array}{c}\text { ACORDO DE PARTICIPAÇÃO NOS } \\
\text { LUCROS E RESULTADOS POR } \\
\text { EMPRESA }\end{array}$ & FINANCEIROS & QUALIDADE & $\begin{array}{l}\text { FLEXIBILIDADE E } \\
\text { CICLOS }\end{array}$ & PRODUTIVIDADE & CLIENTES & RECURSOS HUMANOS \\
\hline 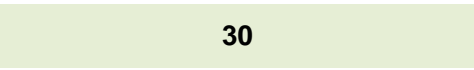 & - & - & - & $\begin{array}{l}\text { Disponibilidade de } \\
\text { Máquinas }\end{array}$ & $\begin{array}{l}\text { Índice de } \\
\text { Satisfação }\end{array}$ & - \\
\hline 31 & - & $\begin{array}{l}\text { Programa de } \\
\text { Melhorias }\end{array}$ & - & $\begin{array}{l}\text { Disponibilidade de } \\
\text { Máquinas }\end{array}$ & $\begin{array}{l}\text { Índice de } \\
\text { Satisfação }\end{array}$ & - \\
\hline 32 & - & 然 & - & $\begin{array}{l}\text { Produtividade, } \\
\text { Disponibilidade de } \\
\text { Máquinas }\end{array}$ & $\begin{array}{l}\text { Índice de } \\
\text { Satisfação }\end{array}$ & - \\
\hline 33 & $\begin{array}{c}\text { Faturamento em novos } \\
\text { negócios, Lucratividade } \\
\text { Bruta, Fluxo de Caixa, } \\
\text { Atraso em Contas a } \\
\text { Receber }\end{array}$ & - & - & . & $\begin{array}{c}\text { Número de } \\
\text { Reclamações }\end{array}$ & - \\
\hline 34 & ( & - & - & Refugo & $\begin{array}{c}\text { Número de } \\
\text { Reclamações }\end{array}$ & Absenteísmo Coletivo \\
\hline 35 & $\begin{array}{l}\text { Vendas, Faturamento, } \\
\text { EBIT, Fluxo de Caixa }\end{array}$ & - & - & - & $e^{2}$ & - \\
\hline 36 & Resultado Empresarial & - & - & Produtividade & - & - \\
\hline 37 & $\begin{array}{c}\text { Faturamento, Resultado } \\
\text { Empresarial }\end{array}$ & - & $\begin{array}{l}\text { Remanufatura de } \\
\text { Motor e Câmbio }\end{array}$ & (2) & - & - \\
\hline 38 & - & - & - & Produtividade & - & - \\
\hline 39 & - & - & - & Produtividade & - & - \\
\hline
\end{tabular}

Fonte: Autores 